\title{
MODEL VEHICLE ROUTING PROBLEM DALAM MENGOPTIMUMKAN RUTE PENGANGKUTAN SAMPAH DI KOTA BOGOR
}

\author{
Maya Widyastiti ${ }^{(1)}$, Isti Kamila ${ }^{(2) *}$
}

\begin{abstract}
Garbage is a common problem that often occurs in many cities, including in Bogor. Every day, the volume of garbage in Bogor reaches 600 tons and only 475 tons can be transported to the Galuga Landfill. However, the vehicle which is owned by the Environmental Agency of Bogor is limited and has certain capacity. In this study, we formulated garbage transportation in the form of a Vehicle Routing Problem model with Branch and Bound method and completed using LINGO 11.0. The optimal solution obtained is a garbage transport route with a minimum distance, and obtained a distance is $1583.24 \mathrm{~km}$, with West Bogor is $172.6 \mathrm{~km}$, Central Bogor is $344.99 \mathrm{~km}$, East Bogor is $298.79 \mathrm{~km}$, North Bogor is $267.4 \mathrm{~km}$, South Bogor is $252.41 \mathrm{~km}$ and Tanah Sareal is $247.05 \mathrm{~km}$. Of the six sub-districts, there was a decrease in the distance of garbage transportation from Temporary Disposal sites to the Galuga Landfill.
\end{abstract}

Keywords: Garbage transportation, Optimization, Vehicle Routing Problem.

\begin{abstract}
Abstrak
Sampah merupakan masalah yang sering terjadi di beberapa kota, termasuk Kota Bogor. Setiap harinya, volume sampah di Kota Bogor mencapai 600 ton dan hanya sekitar 475 ton yang dapat diangkul ke Tempat Pembuangan Akhir (TPA) Galuga. Selain itu, banyaknya armada pengangkut sampah yang dimiliki oleh Dinas Lingkungan Hidup pun terbatas dan memiliki kapasitas tertentu. Pada penelitian ini, kami memformulasikan masalah pengangkutan sampah ke dalam bentuk Vehicle Routing Problem dengan metode Branch and Bound dan diselesaikan menggunakan perangkat lunak LINGO 11.0. Solusi optimal yang diperoleh adalah rute pengangkutan sampah dengan jarak tempuh yang minimum dan diperoleh sebesar $1583.24 \mathrm{~km}$, dengan Bogor Barat sebesar $172.6 \mathrm{~km}$, Bogor Tengah sebesar 344.99 km, Bogor Timur sebesar 298.79 km, Bogor Utara sebesar 267.4 km, Bogor Selatan sebesar $252.41 \mathrm{~km}$ dan Tanah Sareal sebesar $247.05 \mathrm{~km}$. Dari keenam kecamatan, terjadi penurunan jarak tempuh pengangkutan sampah dari beberapa Tempat Pembuangan Sementara (TPS) ke TPA Galuga.
\end{abstract}

Kata kunci: Optimisasi, Pengangkutan Sampah, Vehicle Routing Problem.

\footnotetext{
* Program Studi Matematika, FMIPA, Universitas Pakuan

Email:maya.widyastiti@unpak.ac.id,istikamila@unpak.ac.id
} 


\section{Maya Widyastiti, Isti Kamila}

\section{Pendahuluan}

Persampahan merupakan permasalahan umum yang sering terjadi di perkotaan, termasuk di Kota Bogor. Berdasarkan catatan dari Dinas Lingkungan Hidup (DLH) Kota Bogor, sampah di Kota Bogor setiap harinya mencapai 600 ton dan hanya 475 ton yang dapat diangkut ke Tempat Pembuangan Akhir (TPA) Galuga. Pada umumnya pengangkutan sampah telah dilakukan secara rutin dari Tempat Penampungan Sementara (TPS) dan dibuang ke TPA dengan menggunakan tipe armada tertentu, seperti arm roll truck, dump truck, ataupun container. Banyaknya armada yang dimiliki oleh DLH Kota Bogor masih terbatas dan armada tersebar di setiap kecamatan dengan jumlah yang berbeda. Armada yang ada di setiap kecamatan hanya akan mengangkut sampah di kecamatan tersebut. Selain itu, setiap tipe armada pun memiliki kapasitas tertentu.

DLH Kota Bogor juga memiliki target untuk dapat mengangkut semua sampah dari TPS. Namun, seiring dengan bertambahnya jumlah penduduk di Kota Bogor, volume sampah yang terkumpul pun semakin banyak. Apabila sampah sudah melebihi batas maksimum dari armada tertentu yang digunakan, maka armada pengangkut tersebut tidak dapat mengangkut semua sampah sehingga penumpukan sampah pun terjadi. Oleh karena itu, diperlukan suatu model pengoptimuman rute pengangkutan sampah di Kota Bogor sehingga tidak terjadi penumpukan sampah.

Model pengoptimuman rute pengangkutan sampah ini diharapkan dapat membantu DLH Kota Bogor khususnya bidang persampahan untuk lebih tepat dalam menangani pengangkutan sampah. Model yang akan diperoleh diharapkan membantu dalam meminimumkan jarak tempuh armada DLH Kota Bogor dalam proses pengangkutan sampah. Pada penelitian ini, model pengoptimuman rute pengangkutan sampah menggunakan model Vehicle Routing Problem.

Model Vehicle Routing Problem (VRP) merupakan masalah optimisasi kombinatorial dan Integer Linear Programming dalam menentukan rute optimal untuk dilalui suatu armada atau kendaraan dengan tujuan meminimumkan biaya, jarak, atau waktu tempuh. Pada masalah VRP terdapat beberapa batasan yang harus dipenuhi, yaitu setiap armada harus memulai rute perjalanan dari depot atau tempat produksi, setiap konsumen hanya akan dilayani satu kali oleh satu armada, setiap konsumen mempunyai sejumlah permintaan yang harus dipenuhi, setiap armada memiliki batasan kapasitas, dan tidak terdapat subrute untuk setiap armada.

Pada penelitian sebelumnya, Apriyanti D., dkk pada tahun 2018 [1] telah menganalisis rute truk pengangkutan sampah di Kota Bogor dengan memanfaatkan Sistem Informasi Geografis. Hasil yang diperoleh berupa jumlah konsumsi bahan bakar (solar) dari 88 rute yang dihasilkan yaitu 1131,822 liter atau biaya yang dibutuhkan untuk satu kali pengangkutan sampah sebesar Rp. 5.834.000. Selain itu, model optimasi pengelolaan sampah juga telah diteliti oleh Supriyo P., dkk pada tahun 2016 [4] dengan studi kasus di Kota Jakarta. Model pengangkutan sampah di Kota Bangli juga telah diteliti oleh Saraswati P.N.S, dkk pada tahun 2013 [3] dengan menentukan jumlah dan sebaran TPS yang dibutuhkan, serta menentukan rute pengangkutan, jumlah armada, jenis armada dan pengaturan waktu pengangkutan sampah.

Penelitian ini bertujuan untuk membangun model pengoptimuman rute pengangkutan sampah di Kota Bogor. Penentuan rute pengangkutan sampah tersebut diatur dengan memperhatikan banyaknya armada dalam mengangkut sampah Kota Bogor. Model yang terbentuk diharapkan dapat digunakan untuk menentukan rute armada dalam pengangkutan sampah dengan jarak yang minimum. 


\section{Maya Widyastiti, Isti Kamila}

\section{Model Matematika}

Model matematika yang dibangun merupakan model yang telah dimodifikasi dari model yang dikemukakan oleh Lubis H.A.R., dkk pada tahun 2016 [2]. Modifikasi dilakukan terhadap kendala yang dibutuhkan.

\section{Himpunan}

$K=\{1,2, \ldots, r\}=$ himpunan armada,

$A=\{2,3, \ldots, n\}=$ himpunan TPS,

$B=\{1,2, \ldots, n\}=$ himpunan TPA dan TPS, dengan 1 menyatakan TPA.

\section{Indeks}

$i, j, p=$ indeks untuk menyatakan TPS dan TPA,

$k=$ indeks untuk menyatakan armada.

\section{Parameter}

$q_{i}=$ banyaknya volume sampah di TPS $i$

$a_{k}=$ kapasitas dari armada $k$

$d_{i j}=$ jarak antara TPS $i$ dan TPS $j$

$u_{i k}=$ variabel tambahan apabila TPS $i$ dikunjungi oleh armada $k$

$N=$ banyaknya armada

\section{Variabel keputusan}

$$
x_{i j k}=\left\{\begin{array}{cc}
1, & \text { jika armada } k \text { mengunjungi TPS } j \text { setelah TPS } i \text { dikunjungi } \\
0, & \text { jika selainnya }
\end{array}\right.
$$

\section{Fungsi Objektif}

Fungsi objektif dari permasalahan ini adalah meminimumkan jarak tempuh armada dalam proses pengangkutan sampah dari TPS ke TPA.

$$
\text { Minimumkan } \sum_{i \in B} \sum_{j \in B} \sum_{k \in K} d_{i j} x_{i j k}
$$

\section{Kendala}

Kendala yang harus dipenuhi adalah sebagai berikut:

1. Setiap armada harus berangkat dari TPA dan seluruh armada harus digunakan untuk mengunjungi TPS tertentu,

$$
\sum_{j \in B} x_{1 j k}=1, \forall k \in K \text {. }
$$

2. Setiap TPS akan dikunjungi tepat satu kali oleh satu armada,

$$
\begin{aligned}
& \sum_{k \in K} \sum_{\substack{i \in B \\
i \neq j}} x_{i j k}=1, \forall j \in B, \\
& \sum_{k \in K} \sum_{j \in B} x_{i j k}=1, \forall i \in B .
\end{aligned}
$$




\section{Maya Widyastiti, Isti Kamila}

3. Setiap armada yang mengunjungi suatu TPS pasti akan meninggalkan TPS tersebut,

$$
\sum_{\substack{i \in B \\ i \neq j}} x_{i p k}-\sum_{\substack{j \in B \\ j \neq p}} x_{p j k}=0, \forall p \in B, \forall k \in K .
$$

4. Volume sampah dari suatu TPS yang dikunjungi oleh suatu armada tidak boleh melebihi kapasitas dari armada tersebut,

$$
\sum_{i \in B} \sum_{\substack{j \in B \\ i \neq j}} q_{i} x_{i j k} \leq a_{k}, \forall k \in K .
$$

5. Memastikan tidak terjadi subrute untuk setiap kendaraan

$u_{i k}-u_{j k}+N x_{i j k} \leq N-1, \forall i, j \in B, k \in K$

\section{Hasil dan Pembahasan}

Pada proses pengangkutan sampah, sampah diambil dari setiap TPS kontainer dan kemudian dibuang ke TPA Galuga. Banyaknya TPS kontainer yang tersebar di 6 kecamatan tidak merata. Selain itu, armada yang digunakan adalah jenis arm roll truck dengan kapasitas 6 ton yang jumlahnya pun tidak sama di setiap kecamatan. Data diperoleh dari Dinas Lingkungan Hidup Kota Bogor, sedangkan jarak antar TPS dan TPA diperoleh melalui aplikasi Goolge Maps. Berikut banyaknya TPS kontainer dan armada yang tersedia di setiap kecamatan.

Tabel 1. Data Banyaknya TPS dan armada

\begin{tabular}{lcc}
\hline \multicolumn{1}{c}{ Kecamatan } & Banyaknya TPS & Banyaknya armada \\
\hline Bogor Barat & 12 & 4 \\
Bogor Tengah & 17 & 7 \\
Bogor Timur & 14 & 5 \\
Bogor Utara & 13 & 5 \\
Bogor Selatan & 16 & 4 \\
Tanah Sareal & 17 & 6 \\
\hline
\end{tabular}

Implementasi model Vehicle Routing Problem menggunakan bantuan software LINGO 11.0 memerlukan waktu eksekusi yang cukup lama. Dari 6 kecamatan yang dicari solusinya, 2 kecamatan diinterupsi setelah melakukan running selama lebih dari 24 jam, yaitu kecamatan Bogor Selatan dan Bogor Tengah. Dari hasil tersebut diperoleh total jarak tempuh minimum sebesar $1583.24 \mathrm{~km}$. Rute pengangkutan sampah setiap kecamatan di Kota Bogor dapat dilihat pada Tabel 2 sampai dengan Tabel 7.

Tabel 2. Rute Kecamatan Bogor Barat

\begin{tabular}{clc}
\hline Armada & \multicolumn{1}{c}{ Rute } & Jarak (km) \\
\hline 1 & TPA Galuga - Curug Induk - Giant Yasmin - Gang Kelor - TPA & 42.1 \\
& Galuga & \\
2 & TPA Galuga - Yasmin Sektor 6 - Rumah Sakit Marzuki Mahdi - & 42.8 \\
& Kapuk Loji - TPA Galuga
\end{tabular}




\section{Maya Widyastiti, Isti Kamila}

3 TPA Galuga - Pasar Gunung Batu - Pasir Kuda - Jalan Manunggal -

47.6 TPA Galuga

$4 \quad$ TPA Galuga - Pusdik Intel - Gang Bengkong - Terminal Bubulak - 40.1 TPA Galuga

Tabel 3. Rute Kecamatan Bogor Tengah

\begin{tabular}{clc}
\hline Armada & \multicolumn{1}{c}{ Rute } & Jarak (km) \\
\hline 1 & TPA Galuga - Pasar Depris - TPA Galuga & 42 \\
2 & TPA Galuga - Cilibende - Universitas Pakuan - TPA Galuga & 54 \\
3 & TPA Galuga - RS. PMI - Jalan Roda -TPA Galuga & 51.5 \\
4 & TPA Galuga - IPB Tegallega - Bogor Plaza - TPA Galuga & 51.1 \\
5 & TPA Galuga - Sempur - Regina Pacis - TPA Galuga & 48.2 \\
6 & TPA Galuga - Kantor Batu - Gedong Sawah - Propindo - Mayor & 47.69 \\
& Oking - TPA Galuga & 50.5 \\
7 & TPA Galuga - Superindo - SMP Negeri 7 - Pusdikzi - Jalan MA & \\
\hline & Salmun - TPA Galuga & Total \\
\hline
\end{tabular}

Tabel 4. Rute Kecamatan Bogor Timur

\begin{tabular}{clc}
\hline Armada & \multicolumn{1}{c}{ Rute } & Jarak (km) \\
\hline 1 & TPA Galuga - Taman Pajajaran - Taman Pajajaran 2 - Parung & 65.64 \\
& Banteng - SKI - Mutiara Bogor Raya - TPA Galuga & \\
2 & TPA Galuga - Bakongsi - Lorena -TPA Galuga & 60.85 \\
3 & TPA Galuga - Jalan Riau - Terminal Baranangsiang - Binamarga - & 68.3 \\
& Bogor Medical Center - Sukamulya - TPA Galuga & \\
4 & TPA Galuga - PDAM - TPA Galuga & 52 \\
5 & TPA Galuga - X-One Sukasari - TPA Galuga & 52 \\
\hline
\end{tabular}

Tabel 5. Rute Kecamatan Bogor Utara

\begin{tabular}{|c|c|c|}
\hline Armada & Rute & Jarak (km) \\
\hline 1 & $\begin{array}{l}\text { TPA Galuga - Indraprasta - Plaza Jambu } 2 \text { - Perum. Pabaton - TPA } \\
\text { Galuga }\end{array}$ & 52 \\
\hline 2 & $\begin{array}{l}\text { TPA Galuga - RS. Mulia - Pasar Tanah Baru - Pandu Raya - TPA } \\
\text { Galuga }\end{array}$ & 54.1 \\
\hline 3 & TPA Galuga - Ciparigi - TPA Galuga & 48 \\
\hline 4 & TPA Galuga - Ciparigi - Brimob - TPA Galuga & 53.4 \\
\hline \multirow[t]{2}{*}{5} & $\begin{array}{l}\text { TPA Galuga - Bantar Jati Atas - IPB III - Botanica - RS. Azra - } \\
\text { TPA Galuga }\end{array}$ & 59.9 \\
\hline & Total & 267.4 \\
\hline
\end{tabular}




\section{Maya Widyastiti, Isti Kamila}

Tabel 6. Rute Kecamatan Bogor Selatan

\begin{tabular}{clc}
\hline Armada & \multicolumn{1}{c}{ Rute } & Jarak (km) \\
\hline 1 & TPA Galuga - Bondongan - Warung Bandrek - Paspampres - Bogor & 58.41 \\
& $\begin{array}{l}\text { Nirwana Residence - TPA Galuga } \\
\text { TPA Galuga - RS. Melania - Pamoyanan sari - Batutulis - Warban - }\end{array}$ & 54.9 \\
& $\begin{array}{l}\text { TPA Galuga } \\
\text { TPA Galuga - Ciawi - Jalan Rolita - Perum. Pakuan - Jalan }\end{array}$ & 67.5 \\
& $\begin{array}{l}\text { Pahlawan - TPA Galuga } \\
\text { TPA Galuga - Nutrifood - Dekeng - Perumda - Villa Kebun Raya - }\end{array}$ & 71.6 \\
\hline & TPA Galuga
\end{tabular}

Tabel 7. Rute Kecamatan Tanah Sareal

\begin{tabular}{|c|c|c|}
\hline Armada & Rute & Jarak (km) \\
\hline 1 & TPA Galuga - Sinbad Agung Residence - TPA Galuga & 42 \\
\hline 2 & $\begin{array}{l}\text { TPA Galuga - Taman sari Persada - SMP } 16 \text { - Bukit Cimanggu I - } \\
\text { Bukit Cimanggu II - TPA Galuga }\end{array}$ & 46.75 \\
\hline 3 & TPA Galuga - Lottemart - TPA Galuga & 40 \\
\hline 4 & $\begin{array}{l}\text { TPA Galuga - Sukaresmi - Bogor Indah Plaza (Yogya) - TPA } \\
\text { Galuga }\end{array}$ & 45.9 \\
\hline 5 & $\begin{array}{l}\text { TPA Galuga - Saung Kuring - Blender - Pondok Rumput - Good } \\
\text { Year - Haur Jaya - TPA Galuga }\end{array}$ & 49.8 \\
\hline \multirow[t]{2}{*}{6} & $\begin{array}{l}\text { TPA Galuga - Kedung Badak II - Kedung Badak I - Pasar Jambu } 2 \text { - } \\
\text { Kedung Badak III - TPA Galuga }\end{array}$ & 50.4 \\
\hline & Total & 247.05 \\
\hline
\end{tabular}

Berdasarkan hasil yang diperoleh dengan menggunakan model Vehicle Routing Problem, terjadi penurunan jarak tempuh jika dibandingkan dengan rute yang saat ini diterapkan oleh Dinas Lingkungan Hidup (DLH) Kota Bogor. Perbandingan jarak tempuh antara model Vehicle Routing Problem (VRP) dan rute dari DLH dapat dilihat pada Tabel 8.

Tabel 8. Perbandingan Jarak Tempuh

\begin{tabular}{lccc}
\hline \multicolumn{1}{c}{ Kecamatan } & Model VRP & Rute DLH & Persentase Penurunan \\
\hline Bogor Barat & 172.6 & 180.1 & $4.16 \%$ \\
Bogor Tengah & 344.99 & 359.1 & $3.93 \%$ \\
Bogor Timur & 298.79 & 329.15 & $9.22 \%$ \\
Bogor Utara & 267.4 & 286.2 & $6.57 \%$ \\
Bogor Selatan & 252.41 & 275.2 & $8.28 \%$ \\
Tanah Sareal & 247.05 & 310.1 & $20.33 \%$ \\
\hline
\end{tabular}

\section{Kesimpulan}

Telah diperlihatkan bahwa model Vehicle Routing Problem dapat digunakan dalam mengoptimumkan rute pengangkutan sampah di Kota Bogor. Hasil yang diperoleh adalah total jarak minimum yang ditempuh sebesar $1583.24 \mathrm{~km}$, dengan rincian Bogor Barat sebesar 172.6 


\section{Maya Widyastiti, Isti Kamila}

km, Bogor Tengah 344.99 km, Bogor Timur 298.79 km, Bogor Utara 267.4 km, Bogor Selatan $252.41 \mathrm{~km}$, dan Tanah Sareal $247.05 \mathrm{~km}$. Hal ini menunjukkan adanya penurunan jarak tempuh yang cukup signifikan dalam pengangkutan sampah di Kota Bogor jika dibandingkan dengan rute pengangkutan yang saat ini diterapkan oleh Dinas Lingkungan Hidup Kota Bogor.

\section{Ucapan Terima Kasih}

Penelitian ini didanai oleh dana Kemenristekdikti dengan Surat Keputusan Nomor 110/SP2H/LT/DRPM/2019 dan Perjanjian/ Kontrak Nomor 2654/L4/PP/2019 dan Nomor 34/LPPM-UP/KP-PDP/III/2019. Ucapan terima kasih ini juga ditujukan kepada semua pihak terkait sehingga penelitian ini dapat terlaksana dengan baik.

\section{Daftar Pustaka}

[1] Apriyanti, D., Kresnawati, D.K., Diniyah, W.F. 2018. Pemanfaatan sistem informasi geografis untuk analisis rute truk pengangkutan sampah di kota bogor. Prosiding Seminar Nasional Geomatika. Badan Informasi Geospasial, Bogor.

[2] Lubis, H.A.R., Maulana, A., Frazila, R.B. 2016. Penerapan Konsep Vehicle Routing Problem dalam Kasus Pengangkutan Sampah di Perkotaan. Jurnal Teknik Sipil, Vol. 23, no 2, hal. $213-222$.

[3] Saraswati, P.N.S., Dharma, I.G.B.S., Sudipta, I.G.K. 2013. Model Pengangkutan Sampah di Kota Bangli. Jurnal Spektran, Vol. 1, no. 2, hal. 24 - 29.

[4] Supriyo, P.T., Aman, A., Bakhtiar, T., Hanum, F. 2017. Model Optimasi Pengelolaan Sampah Perkotaan: Penentuan Lokasi Pembuangan Sampah. Prosiding Seminar Nasional Matematika X UNNES, Vol.1, no.1 tahun 2017, hal 701-708. Jurusan Matematika, Fakultas Matematika dan Ilmu Pengetahuan Alam, Universitas Negeri Semarang, Semarang. 